\title{
POLÍTICAS PÚBLICAS INCLUSIVAS NA EDUCAÇÃO BÁSICA: REFLETINDO SOBRE A SITUAÇÃO DO ESTUDANTE SURDO NAS ESCOLAS DE JOÃO PESSOA/PB
}

\author{
Sandra Alves da Silva Santiago ${ }^{1}$
}

\section{INTRODUÇÃO}

Não há como negar que as políticas públicas brasileiras têm avançado consideravelmente nas últimas décadas, no sentido da democratização do acesso e na busca da qualidade do ensino, especialmente na educação básica. Com relação às pessoas com deficiência, admitimos que os avanços são ainda maiores, pois numa retrospectiva histórica, não faz muito tempo, estavam estes sujeitos privados do direito de estudar. É somente nos anos 70 que se inicia um movimento em prol do acesso de alunos com deficiência à rede regular de ensino, buscando-se assegurar-lhes os mais legítimos direitos humanos há muito perseguidos por uma população vitimada muito mais pelo preconceito social do que pela condição de deficiência que possui.

De modo geral, a proposta que emerge a partir dos anos 70 se pauta na ideia da "normalização dos sujeitos" com deficiência, e a este modelo deu-se o nome de Integração. 0 modelo de Integração tinha por base a matrícula inicial do aluno com deficiência nas classes ou escolas especiais, para que na medida em que ele fosse adquirindo as condições necessárias, pudesse ser encaminhado para o ensino regular. Com o tempo, este modelo foi se revelando incapaz de acabar com o preconceito e a discriminação, e ineficaz para habilitar o aluno para tomar parte das oportunidades educacionais previstas para o conjunto da escola. Estes resultados foram pouco a pouco apontando para um novo caminho educativo, denominado de Inclusão.

De certa forma, a inclusão é a primeira oportunidade real que os alunos com deficiência vislumbram de usufruir o direito à educação, com equidade e justiça social. De acordo com Mantoan (2001), a inclusão é um paradigma a partir do qual se muda a imagem da escola. Para a autora, pode-se dizer que a inclusão é uma espécie de provocação, cuja intenção é melhorar a qualidade do ensino das escolas, atingindo todos os alunos, com ou sem deficiência (MANTOAN, 2001).

\footnotetext{
${ }^{1}$ Professora adjunta do DHP/CE/UFPB.
} 
Outro aspecto que merece ser destacado é que, com a inclusão, supera-se a ideia de classificação e definição dos indivíduos em função de suas deficiências, abandonando-se, por conseguinte, os critérios de distinção entre deficientes e não deficientes, com dificuldades e sem dificuldades, com limitações e sem limitações, normais e anormais, porque se entende que todas as pessoas possuem diferenças e dificuldades temporárias ou permanentes, cabendo à escola, bem como a sociedade, encontrar formas de acolher a todos.

Enquanto paradigma, podemos dizer que a educação inclusiva se baseia, então, na construção de um modelo diferente de escola, portanto, de currículo, de planejamento, de formação, de metodologias, etc. Neste novo modelo superam-se os rótulos, tão comuns ao atendimento de pessoas com deficiência e busca-se instalar outra ótica sobre os indivíduos e grupos, a partir de um modelo explicativo social das deficiências, entendendo que a maioria dos obstáculos que estas pessoas enfrentam está mais na sociedade que não está preparada para recebê-las do que nelas próprias. Quanto a isso, Sassaki salienta que os problemas da pessoa com deficiência,

[...] não estão nela tanto quanto estão na sociedade. Assim, a sociedade é chamada a ver que ela cria problemas para as pessoas portadoras de necessidades especiais ${ }^{2}$, causando-lhes incapacidades no desempenho de papéis sociais $(1997$, p. 47).

Diante disto, compreendemos que é tarefa de todos, modificar a sociedade para torná-la capaz de acolher todas as pessoas que, uma vez incluídas poderão ter atendidas suas necessidades, comuns e especiais. É preciso, portanto, vivificar o paradigma educacional de inclusão do aluno na escola por toda a educação básica, guiados pelo princípio de educação como direito de todos e por toda a vida, sendo a escola constantemente adaptada às necessidades de cada um.

Nesse sentido, Glat (1998:27) chama nossa atenção para o importante papel que assume o sistema escolar, colocando neste ponto o alicerce para a consolidação da escola inclusiva. A própria legislação brasileira, através do Decreto no 7.611 defende a existência de "um sistema educacional inclusivo em todos os níveis, sem discriminação e com base na igualdade de oportunidades" (BRASIL, 2011, ARTIGO 1으). Desse modo, fica evidente que nesta

\footnotetext{
${ }^{2}$ Esta expressão não é mais usada, pois é muito ampla. Segundo a Política Nacional na perspectiva da educação inclusiva, a educação especial passa a integrar a proposta pedagógica da escola regular, promovendo o atendimento às necessidades educacionais especiais de alunos com deficiência, transtornos globais de desenvolvimento e altas habilidades/superdotação.
} 
nova conjuntura social e política da educação brasileira, não cabe mais abandonar o aluno com deficiência a própria sorte, nem tampouco responsabilizá-lo por suas dificuldades.

Nesta perspectiva, a escola precisa ser reestruturada para atender às necessidades educacionais dos seus alunos, tendo estes limitações ou não. Portanto, desde o currículo, os métodos, a avaliação, bem como a formação de professores são postos na legislação desde a década de 90, como importantes espectros de ação para que se efetive uma reinvenção da escola. Nesta direção, a Lei de Diretrizes e Bases da Educação Nacional (LDB, no 9.394) aponta a urgência que os sistemas de ensino assegurem aos educandos com deficiência, transtornos globais do desenvolvimento e altas habilidades ou superdotação, condições compatíveis com as necessidades dos alunos. A LDB dá pistas quanto $\mathrm{a}$ isso quando destaca:

(...) currículos, métodos, técnicas, recursos educativos e organização específicos, para atender às suas necessidades;

Terminalidade específica para aqueles que não puderem atingir o nível exigido para a conclusão do ensino fundamental, em virtude de suas deficiências, e aceleração para concluir em menor tempo o programa escolar para os superdotados;

Professores com especialização adequada em nível médio ou superior, para atendimento especializado, bem como professores do ensino regular capacitados para a integração desses educandos nas classes comuns (BRASIL, 1996, ARTIGO 59).

Assim, fica evidente que pensar a escola inclusiva é o mesmo que pensar uma escola onde caibam todos os alunos. E só caberão todos os alunos numa escola que se abre ao novo, aprende com os diferentes, busca oferecer as condições de aprendizagem e acessibilidade legítimas a cada grupo ou indivíduo, sem excluir ninguém.

Numa escola inclusiva, segundo nossa legislação a oferta do Atendimento Educacional Especializado - AEE, sendo este compatível para cada necessidade apresentada pelos grupos que compõem a educação especial. De acordo com o Decreto 7.611, a "educação especial deve garantir os serviços de apoio especializado voltado a eliminar as barreiras que possam obstruir o processo de escolarização de estudantes com deficiência, transtornos globais do desenvolvimento e altas habilidades ou superdotação" (BRASIL, 2011, ART. 2º).

Segundo o mesmo decreto, o AEE consiste num "conjunto de atividades, recursos de acessibilidade e pedagógicos organizados institucional e continuamente", com o objetivo de: 
Prover condições de acesso, participação e aprendizagem no ensino regular e garantir serviços de apoio especializados de acordo com as necessidades individuais dos estudantes;

Garantir a transversalidade das ações da educação especial no ensino regular;

Fomentar o desenvolvimento de recursos didáticos e pedagógicos que eliminem as barreiras no processo de ensino e aprendizagem; e

Assegurar condições para a continuidade de estudos nos demais níveis, etapas e modalidades de ensino (op. Cit, artigo 3으).

\section{Por uma Educação Inclusiva para Surdos}

É importante considerar que na construção do paradigma da inclusão, bem como na sua consolidação, concorrem forças diversas e, por vezes, até antagônicas que emergem dos diversos grupos que constituem a sociedade civil e que representam, por sua vez, interesses legítimos de grupos e pessoas. É a partir dessa compreensão que se busca ler na realidade da pessoa com surdez o resultado de incessantes lutas por emancipação e garantia de direitos, mas que se encontra atravessado por inúmeras contradições próprias do desenvolvimento humano, destacando-se aí o lugar reservado às políticas públicas e, particularmente, à política educacional, que não é neutra, e traz consigo concepções e práticas a respeito da pessoa surda, de sua língua e de seu modo de estar e apreender o mundo.

Dessa forma, apoiados em Vieira (2000) acrescenta-se a estas questões, a compreensão de que, na maioria das vezes, a política educacional, ao contrário do que se espera, passa muito longe de guiar-se pelos instrumentos legais, pois se vê perpassada por valores, princípios que podem ser vistos e traduzidos no cotidiano. Sobre a política educacional, Vieira (1992) também acrescenta que:

\footnotetext{
A política educacional não resulta apenas da deliberação exclusiva da burocracia. Antes constitui-se como fruto da complexa relação que se estabelece entre o Estado e as forças sociais que logram êxito em fazer valer seus interesses junto ao aparato estatal (1992, p. 1-3).
}

Neste sentido, não podemos esperar que apenas a promulgação de dispositivos legais determinem e promovam a política inclusiva, pois se assim fosse, nosso país seria um país inclusivo, pois estamos fartos de legislação nesta direção. Contudo, há forças sociais que impulsionam noutra direção e, que no caso das pessoas surdas são constantemente influenciadas pelo olhar do ouvinte sobre o surdo. Por isso, nas lutas surdas tem se 
evidenciado uma desvantagem enorme, pois a "fala" do surdo é sempre mediada por um ouvinte e neste processo, na maioria das vezes, é silenciada.

Como a língua e a linguagem são os grandes instrumentos da sociedade moderna para registrar seus direitos, e tendo o surdo, fortes diferenças linguísticas que o obrigam a necessitar de intérprete de Libras para dialogar nas diferentes instâncias onde são travadas lutas em prol da inclusão, tem ficado a pessoa com surdez a mercê de um discurso interpretado, indireto, incompleto, pois quase sempre é destituído de emoção, envolvimento e verdade que somente o próprio sujeito de direitos é capaz de expressar em sua plenitude (SANTIAGO, 2011).

De um lado, temos o próprio surdo, representado principalmente pelas associações e federações de surdos de todo país, mas, ainda sem "voz" própria, e de outro, pelos profissionais que trabalham na área da educação especial ou pelos gestores que definem as ações políticas de um governo ou mesmo do Estado, mas que são todos ouvintes. Entre os surdos estão os legítimos usuários da política pública que tem posicionamentos bem claros e definidos a respeito da inclusão, mas que não falam diretamente ao Estado ou à população, pois, tendo sua língua natural ou primeira língua desconhecida pela maioria, resta apenas utilizar-se do intérprete de Libras - Língua Brasileira de Sinais.

Àqueles que deveriam ser os protagonistas das políticas públicas para pessoas com surdez, ou seja, os surdos reivindicam uma escola inclusiva, mas, compreendem-na dentro de uma perspectiva bilíngue ${ }^{3}$, ou seja, considerando suas diferenças linguísticas, o uso da Libras como primeira língua, e o aprendizado do português como segunda língua. Por sua vez, este entendimento de inclusão e de identidade linguística impõe diferenças substantivas na organização escolar que vão desde a construção curricular, organização das classes, língua de comunicação e compreensão a ser adotada, bem como nos recursos utilizados e profissionais envolvidos.

De acordo com Lacerda \& Mantelatto (2000) o bilinguismo enquanto paradigma educacional tem por princípio a exposição da criança surda à língua de sinais desde mais tenra idade, pois compreende que esta aquisição precoce pode propiciar um desenvolvimento pleno de linguagem para a criança surda, ao passo que este fator tem consequências no desenvolvimento da pessoa surda, influenciando diretamente sua aprendizagem.

\footnotetext{
${ }^{3}$ A partir de um conceito mais geral de bilinguismo este seria determinado pelo uso de duas línguas. Na questão que interessa a este artigo, o bilinguismo é determinado pela situação sócio cultural da comunidade surda, e pelo uso de duas línguas no processo educacional: a Língua Brasileira de Sinais e a Língua Portuguesa.
} 
Os gestores, na sua maioria, sem formação na área e informação suficiente a respeito da surdez, compreendem que a inclusão do estudante surdo se pauta essencialmente pela presença do intérprete/tradutor de libras em sala de aula. O problema maior é que este entendimento não está em acordo com os discursos e reivindicações dos surdos, nem com as políticas públicas inclusivas para o grupo, que são confusas, precárias e ouvintistas, pois se pautam no modelo ouvinte, desconsiderando a contribuição da comunidade surda.

\section{As Diferenças inerentes à Surdez e a Necessidade de uma Escola Bilíngue}

O fato de apresentar diferenças linguísticas gera para a comunidade surda, que hoje é de aproximadamente $10 \%$ da população brasileira, importantes obstáculos, que acabam fomentando sua exclusão social. Outras condições de deficiência como a cegueira ou a paralisia cerebral, por exemplo, também colocam as pessoas na situação de exclusão social, em suas mais diferentes expressões, confirmando que ainda estamos longe de nos aceitarmos indistintamente. Entretanto, consideramos que a situação da pessoa surda é especialmente importante no discurso inclusivo porque envolve um elemento importante para a socialização, aprendizagem e constituição subjetiva dos sujeitos: a linguagem (SANTIAGO, 2011).

Dessa forma, mesmo sendo evidente que os avanços da ciência e da tecnologia trouxeram importantes conquistas ao homem e a mulher moderna, oportunizando acesso ao conhecimento socialmente construído, e de que a legislação brasileira já avançou muito nesta direção, é preciso admitir que este saber não está, ainda, ao alcance de todos. No caso dos sujeitos surdos, pela ausência de audição e desenvolvimento natural de uma língua diferente da língua padrão do país onde se nasce, de natureza completamente diversa da língua oral, posto que a Língua de sinais é de modalidade viso-espacial, temos uma situação de aprendizagem altamente comprometida com afetação em outras áreas do desenvolvimento como a cognição e a socialização (FERNANDES, 1995).

O fato de utilizar a língua de sinais para comunicar-se leva os surdos a lacunas muito profundas na sua escolarização. Contudo, Lacerda (2006) chama nossa atenção para o fato de que pesquisas em todo o mundo revelam que sujeitos surdos que passaram por vários anos de escolarização apresentam competências para atividades acadêmicas muito aquém dos ouvintes, apesar de terem suas condições cognitivas iniciais semelhantes aos demais. Com isto, a autora denuncia a existência de uma inadequada estrutura de ensino para os surdos, responsável pelo fracasso escolar destes alunos. 
O despreparo das escolas, dos professores e até mesmos dos especialistas na área corroboram para que o surdo não ascenda educacionalmente. Os dados do último censo (2010) comprovam esta afirmativa, quando revelam que há no Brasil, mais de 5 milhões de pessoas com problemas auditivos, e que apenas 974 surdos estavam cursando o nível superior naquele ano. Este panorama é grave e demonstra o que já se prevê em alguns dispositivos legais e orientações do Ministério da Educação (MEC): de que os surdos - como outros grupos - necessitam de um olhar diferenciado e de que a escola esteja preparada para atender suas necessidades.

Dispomos de dispositivos legais que já asseguram os direitos linguísticos dos surdos, mas, estamos longe de efetivá-los na prática. A lei 10.436, de 2002, que dispõe sobre a língua brasileira de sinais dá sinais claros de reconhecimento da diferença do surdo e da necessidade de que a sociedade se organize para melhor acolher estes indivíduos. Na mesma direção, o Decreto 5.626, de 2005, que regulamenta a lei anterior, reconhece que a pessoa surda é aquela, "por ter perda auditiva, compreende e interage com o mundo por meio de experiências visuais, manifestando sua cultura principalmente pelo uso da Língua Brasileira de Sinais - Libras" (BRASIL, 2005, ART. 2ㅇ).

A partir deste entendimento, o decreto passa a fazer considerações de natureza curricular, que é urgente para o sucesso do modelo de inclusão que se pretende para surdos e

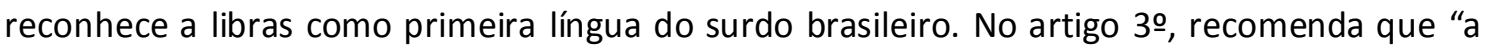
Libras seja inserida como disciplina curricular obrigatória nos cursos de formação de professores", (...) em instituições de ensino, públicas e privadas (Ibdem).

Ainda é importante destacar que, de acordo com a legislação vigente, o ensino da modalidade escrita da Língua Portuguesa deve ser visto como "segunda língua para pessoas surdas", o que aponta na direção da perspectiva bilíngue na educação de surdos, onde o aluno está imerso na aprendizagem de duas línguas, sendo a Libras a sua primeira língua, pois que é sua língua natural, e do português escrito como segunda língua, já que é a língua do seu país (BRASIL, 2005, ART. 13ㅇ).

Neste contexto, Skliar (2009) esclarece que discutir a educação inclusiva para surdos implica em considerar sua natureza indiscutivelmente bilíngue. E, nesse sentido o bilinguismo, conforme salienta o autor, tem um valor político que além de construção histórica, cultural e social, também precisa ser considerado como "relações de poder e conhecimento que atravessam e delimitam a proposta e o processo educacional" (2009, p. 7). 
Sendo assim, ao investigar as políticas de inclusão que se desenvolvem no cotidiano das escolas públicas é necessário analisá-las dentro de um entendimento sobre a surdez que superem as visões reducionistas, colonialistas ou ouvintistas. Segundo Lacerda (2006:167), a inclusão "é um processo gradual e dinâmico que pode assumir formas diversas a depender das necessidades dos estudantes", e no caso dos surdos, deve propiciar "a construção de processos linguísticos adequados, de aprendizagem de conteúdos acadêmicos e de uso social".

É fato que nossa legislação assegura a matrícula dos alunos surdos na rede regular de ensino, e ainda garante o atendimento educacional especializado para cada caso, sempre que se fizer necessário. Portanto, em termos da política pública anunciada temos a inclusão de surdos, Mas, o que não se sabe é se a proposta veiculada nas escolas brasileiras atendem as necessidades dos estudantes surdos e realizam a inclusão.

Conforme assegura a LDB 9.394 (1996), as Diretrizes Curriculares para a Educação Especial na Educação Básica (2001) e a Política Nacional da Educação Especial na perspectiva da Educação Inclusiva (2008), os alunos com deficiência deverão se beneficiar do ensino regular, mas, sempre que necessário, usufruir do atendimento especializado para vencer obstáculos que se apresentem no seu desenvolvimento e aprendizagem.

Para os surdos, o AEE consiste em três tipos de atendimento: a) atendimento educacional especializado em libras na escola comum; b) atendimento educacional especializado para o ensino de libras na escola comum e c) o atendimento educacional especializado para o ensino de língua portuguesa.

No que se refere ao AEE em Libras na escola comum, Damázio (2007) esclarece que se trata de um momento em que "todos os conhecimentos dos diferentes conteúdos curriculares, são explicados nessa língua por um professor, sendo o mesmo preferencialmente surdo". Ainda para a autora, esse trabalho deve ser realizado todos os dias em horário contrário ao da escola comum (DAMÁZIO, 2007:25).

Quanto ao AEE para o ensino de Libras na escola comum, é um momento no qual os alunos surdos "terão aula de Libras, favorecendo o conhecimento e a aquisição principalmente de termos científicos". Segundo Damázio, este tipo de atendimento deve ser realizado pelo professor e/ou instrutor de Libras, de acordo com o nível de desenvolvimento que o aluno se encontra na Libras, portanto, varia de surdo para surdo. Mas, também deve acontecer diariamente (Ibdem).

Sobre o AEE para o ensino de Língua Portuguesa, a mesma autora esclarece que este é um momento onde devem ser trabalhadas as especificidades desta língua para as pessoas 
surdas. Para ela, este trabalho deve ser realizado todos os dias, por uma professora de Língua Portuguesa, e pautado no conhecimento que o aluno surdo tem dessa língua (op. Cit.).

Diante disto, investigamos durante o período 2012-2013 como vinha se desenvolvendo a política inclusiva nas EPs de João Pessoa, tendo por base o AEE para surdos.

\section{A Pesquisa}

O presente trabalho se pautou numa pesquisa de natureza qualitativa, se constituindo de caráter explicativo e exploratório e se desenvolveu a partir de três etapas específicas: primeiro realizamos um estudo bibliográfico sobre a temática da surdez, além de um levantamento dos principais documentos relativos à inclusão de surdos. Em seguida, realizamos uma pesquisa de campo, junto às Escolas Polos (EPs) de João Pessoa, onde se optou pela observação com registro e a entrevista com os gestores. Participaram das entrevistas 09 gestores, assim identificados: $A, B, C, D, E, F, G, H$ e I. Na terceira etapa, procedemos à análise dos dados coletados a partir da observação e nas entrevistas.

No estudo bibliográfico focalizamos as produções sobre a educação inclusiva, a educação de surdos, da legislação vigente e o AEE.

De posse da autorização para realização da pesquisa de campo, buscamos conhecer a realidade de todas as escolas consideradas polos pela Secretaria de Educação do Município de João Pessoa, onde realizamos as observações com registro em diário de campo, além de entrevista com gestores. A pesquisa ocorreu entre 2012 e 2013 em 07 polos onde existiam surdos matriculados, totalizando $09 \mathrm{EPs}$, tendo em vista que dois polos possuem duas escolas que recebem surdos.

\section{Resultados e Discussões}

Segundo dados da Secretaria de Educação de João Pessoa existem atualmente 09 (nove) polos que compõem as regiões político administrativas do município. No entanto, em apenas 07 (sete) deles existem surdos regularmente matriculados. Por isso, nossa pesquisa ocorreu somente nestes 07 polos. Por outro lado, cabe destacar que os polos 01, 02, 05, 07 e 09 dispõem de uma (01) escola cada. No entanto, os polos 03 e 04 dispõem de duas (02) escolas no mesmo polo, o que totaliza 09 escolas que recebem surdos no município.

As "Escolas Polos (EPs)" foram apontadas pela própria secretaria de educação como as escolas de referência para o atendimento de alunos surdos. São as seguintes: 
Quadro 1: Polos e Escolas

\begin{tabular}{|c|c|}
\hline POLO & ESCOLA \\
\hline 01 & Escola Municipal Índio Piragibe \\
\hline 02 & Escola Municipal Durmeval Trigueiro Mendes \\
\hline 03 & Escola Municipal Arnaldo de Barros Moreira \\
& Escola Municipal João Santa Cruz \\
\hline 04 & Escola Municipal Padre Leonel da Franca Municipal Fenelon Câmara \\
\hline 05 & Escola Municipal Governador Leonel Brizola \\
\hline 07 & Escola Municipal Professora Anayde \\
\hline 09 & Escola Municipal Zulmira de Novais \\
\hline
\end{tabular}

Fonte: PIBIC, 2012.

Com os dados das EPs em mãos, passamos a desenvolver as demais etapas da pesquisa através da organização de um cronograma de visitas. Durante este período designado para cada escola foram feitas: apresentação dos pesquisadores, coleta de dados referentes à matrícula dos estudantes surdos e serviços e profissionais existentes, além do agendamento das entrevistas com os gestores de cada escola. No quadro 2 apresentamos o quantitativo de alunos surdos, por escola/polo:

Quadro 2: Quantitativo de surdos por polo

\begin{tabular}{|c|c|}
\hline POLO & QUANTITATIVO DE ALUNOS SURDOS \\
\hline POLO 1 - Escola Municipal Índio Piragibe & 38 \\
\hline POLO 2 - Escola Municipal Durmeval Trigueiro & 07 \\
\hline POLO 3 - Escola Municipal Arnaldo de Barros & 07 \\
Moreira & 09 \\
Escola Municipal João Santa Cruz & 07 \\
\hline POLO 4 - Escola Municipal Padre Leonel da Franca & 03 \\
\hline Escola Municipal Fenelon Câmara & 04 \\
\hline BOLO 5 - Escola Municipal Governador Leonel & \\
\hline
\end{tabular}




\begin{tabular}{|c|c|}
\hline $\begin{array}{c}\text { POLO 7 - Escola Municipal Professora Anayde } \\
\text { Beirys }\end{array}$ & 09 \\
\hline POLO 9 - Escola Municipal Zulmira de Novais & 10 \\
\hline
\end{tabular}

Fonte: PIBIC, 2012/2013.

A partir dos dados acima foi possível observar que há uma variação muito grande entre as escolas no que diz respeito à quantidade de alunos surdos matriculados. Esta disparidade não foi bem explicada pelas escolas, mas, em entrevista, alguns gestores esclarecem que o motivo são os próprios surdos que divulgam uns para os outros onde estão estudando, atraindo outros para o mesmo ambiente. Segundo os gestores, os próprios surdos argumentam que é melhor estudar onde existem muitos iguais a ele, com quem possa se comunicar. É desse modo, que a Escola Índio Piragibe conta com 38 surdos enquanto a média das outras escolas é de 07 surdos.

Cabe destacar neste dado que, esta variação no quantitativo de alunos por escola deveria refletir na política inclusiva, especialmente no que diz respeito à distribuição dos recursos e encaminhamento de profissionais para atendimento especializado. No entanto, este fato não se traduz nas políticas inclusivas das EPs de João Pessoa, conforme se constata no quadro a seguir, onde apresentamos a relação estudantes surdos-intérpretes de Libras:

Quadro 3: Relação estudantes surdos - intérpretes de Libras:

\begin{tabular}{|c|c|c|c|}
\hline POLO & $\begin{array}{c}\text { QUANTITATIVO DE } \\
\text { SURDOS }\end{array}$ & $\begin{array}{c}\text { QUANTITATIVO DE } \\
\text { INTÉRPRETES }\end{array}$ & $\begin{array}{c}\text { PERCENTUAL INTÉRPRETE } \\
\text { PARA CADA SURDO }\end{array}$ \\
\hline 01 & 38 & 11 & 0,28 \\
\hline 02 & 07 & 03 & 0,42 \\
\hline 03 & $07+09=16$ & $02+04=06$ & 0,37 \\
\hline 04 & $09+03=12$ & $03+01=04$ & 0,33 \\
\hline 05 & 04 & 02 & 0,22 \\
\hline 07 & 09 & 08 & 0,89 \\
\hline 09 & 10 & 06 & 0,60 \\
\hline
\end{tabular}

Fonte: PIBIC, 2012/2013.

Conforme se observa no quadro acima, a distribuição dos intérpretes não é equitativa. Somente nos polos 07 e 09 observamos uma distribuição de boa a ótima, pois um 
intérprete atende a menos de dois alunos, o que pode tornar melhor a qualidade da atividade de interpretação.

Outro aspecto que identificamos ao longo das observações nas EPs é o fato de que a distribuição dos intérpretes obedece a critérios que não atingem a todos os alunos. Portanto, numa escola que possui 06 intérpretes para 10 alunos, e apresenta um percentual alto $(0,60)$, ainda há aluno que não recebe nenhum apoio do intérprete porque está matriculado noutro turno, onde o intérprete não atua. Soma-se o fato de que a secretaria não envia novo intérprete porque se pauta apenas no quantitativo que já existe de intérpretes na escola. Desse modo, as observações nos demostraram que apenas 02 (duas) EPs em todos os polos contavam com intérprete de libras em todas as turmas que existem surdos. Nota-se, portanto, uma incoerência na distribuição dos profissionais, o que repercute no atendimento dos alunos surdos e não atende ao que prevê a legislação, nem as necessidades dos surdos.

\section{A Entrevista com Gestores}

No tocante aos gestores, a partir das entrevistas, pontuamos algumas questões que nos parecem muito relevantes para nossa análise, as quais apresentamos da seguinte forma: a) A percepção dos gestores sobre os estudantes surdos; b) A inclusão como política pública; c) A oferta do AEE para os estudantes surdos.

\section{a) A percepção dos gestores sobre os estudantes surdos}

Quando questionados sobre a presença dos estudantes surdos nas EPs, obtivemos diferentes respostas que apontam para a dificuldade, o obstáculo, o problema de se ter alunos surdos na escola. Destacamos a seguinte:

"Considero um pouco complicado" (gestor F).

Não me acho preparado para lidar com alunos com deficiência" (gestor B).

Quando insistimos acerca dessa "complicação" a que o gestor se referiu, obtivemos como explicação a falta de apoio da família. Outros gestores falaram sobre a falta de conhecimento escolar (gestores D, G, H), e do difícil relacionamento entre os alunos surdos e os demais alunos da escola, em virtude de certo preconceito (gestor A, I). Esse tipo de resposta 
é bem ilustrativo do que ocorreu com os gestores, pois eles demonstraram nitidamente sentirem dificuldade para lidar com a presença do aluno com deficiência na escola e destacaram que esta limitação se situa principalmente na questão da comunicação.

Alguns gestores ainda afirmaram que "a maioria das pessoas da escola não sabe língua de sinais" ( $A, C, E)$, embora a legislação reconheça que a Libras é a primeira língua do surdo e defenda que a mesma seja assim utilizada nas escolas brasileiras.

\section{b) A Inclusão como Política Pública}

Quando questionamos à inclusão como política pública, os gestores demonstraram grande desconhecimento sobre o assunto, e explicaram que não possuem formação na área (gestor B, C, D, E, F), nem capacitação oferecida pela rede municipal neste sentido $(A, G, H, I)$, o que de certa forma, os desresponsabilizava sobre a temática.

A fim de aprofundar a questão fizemos questionamentos a respeito do Projeto Político Pedagógico (PPP) da escola, pois gostaríamos de saber se há propostas inclusivas para os surdos no referido documento. Os resultados revelaram que 07 (sete) gestores entrevistados têm conhecimento do PPP de sua escola (B, C, E, F, G, H, I), e 02 (dois) gestores assumem que ainda não conhecem o documento, por isso não sabiam informar se há ações inclusivas previstas (A, D). Contudo, dos 07 gestores que conhecem o PPP da escola, apenas 04 (quatro) indicam que o documento possui alguma ação inclusiva prevista (C, D, H, I), enquanto 03 (três) deles dizem não ter certeza (B, F G).

Diante dos dados, solicitamos ver o PPP das 04 escolas que, segundo os gestores, possuíam medidas inclusivas, a fim de identificar quais eram estas ações e se contemplavam as necessidades dos surdos. Apenas 01 gestor se dispôs a fazê-lo, mostrando conhecimento, inclusive, de que ação seria essa (C), enquanto os demais apresentaram obstáculos para não mostrar o documento. Tais desculpas variaram entre "não tenho a chave $(H)$, não sei onde está (I) ou estou com pressa (D)".

\section{c) Sobre o AEE para os estudantes surdos}

Quando questionamos sobre o AEE para surdos, os resultados revelam que das 09 EPs, cinco (05) escolas não possuem o local adequado para o atendimento $(A, B, C, F, I)$, ou seja, não possuem a Sala de Recursos Multifuncionais. Algumas estão em construção, outras não possuem nenhum espaço disponível. Apenas 04 escolas ( $C, D, E, G)$ possuem a referida 
sala funcionando, ainda que não ofereça os três atendimentos previstos na Política Nacional de Educação Especial na perspectiva da Educação Inclusiva (2008), para os surdos.

Diante da constatação, buscamos entender como ocorre a relação entre os estudantes surdos e os professores, e que tipo de apoio o aluno recebe, na inexistência do AEE. Ficou evidente que o único serviço que existe em todas as escolas é a presença do intérprete de Libras, embora, este não esteja disponível a todos os surdos.

Buscamos identificar como se dava o AEE para surdos, nas escolas que possuíam salas de Recursos Multifuncionais, e o resultado revelou que nenhuma das Eps oferece o serviço previsto na legislação, ou seja, "AEE para o ensino de Libras", "AEE para o ensino em Libras" e "AEE para o ensino de Língua Portuguesa". Portanto, não há efetivamente uma política que atenda as necessidades dos estudantes surdos, nem na perspectiva defendida pelos gestores, ou seja, de "inclusão em sala regular, com AEE e intérprete", nem da perspectiva defendida pelos surdos "inclusão a partir de um modelo bilíngue de educação", tendo Libras como primeira língua sendo utilizada em todos os ambientes escolares, e não apenas na sala de aula e pelo intérprete.

Quanto à presença do intérprete de libras, evidenciamos que estão presentes em todas as escolas e que são identificados pelos gestores como a principal ação em prol da inclusão de surdos. Na fala dos gestores, fica claro que eles são vistos como suficientes para a aprendizagem dos surdos.

Diante disto, buscamos compreender como ocorre a comunicação do aluno com o professor e demais profissionais da escola. De acordo com as respostas dos gestores fica claro que nas escolas dos gestores $A, C, D, E, F$, os alunos surdos se comunicam somente entre eles, formando verdadeiros subgrupos. Nas escolas dos gestores $B, G, H, I$, os gestores admitem que há uma relativa interação entre ambos (professores e demais alunos), mas, reconhecem que a interação é melhor com o intérprete. Portanto, quando este falta é um caos.

Segundo os gestores A e F "as comunicações entre os professores e alunos surdos são através de mímicas ou gestos", pois "os professores não tem tanto interesse em aprender tal língua" (gestor C, D). Essa informação dada pelos gestores pode ser constatada a partir das observações que realizamos nas EPs. Vimos que a maioria dos profissionais das EPs tem pouco conhecimento da Libras, muitos não se interessam, outros acham difícil. E, desse modo, a maioria não se comunica diretamente com os alunos surdos, tal relação é sempre intermediada pelo intérprete de Libras. E, quando este profissional não está, não há nenhuma interação do aluno com os professores. 


\section{CONCLUSÕES}

Conseguimos reconhecer os avanços que as políticas públicas conferiram nas últimas décadas à educação brasileira. Reconhecemos, inclusive, os avanços trazidos pelos textos legais, no sentido de garantir direitos sociais, com destaque para a educação como direito de todos e por toda a vida, clamando a sociedade para que respeite a pessoa com surdez e reconheça ali um sujeito de direitos, que é diferente linguisticamente e, que por isso, necessita de um AEE que se volte às suas necessidades. Contudo, é preciso admitir que o fato das escolas hoje não rejeitar os alunos surdos, não negar a matrícula, não discriminar abertamente sua língua e até discursar em favor da língua de sinais não pode ser entendido como inclusão.

A aceitação das diferenças é, sem sombra de dúvida, um significativo avanço em prol da inclusão, mas, ela só se consolida se pensarmos numa outra lógica para a escola, ou numa outra escola para surdos, onde eles sejam respeitados.

Não podemos nos contentar apenas com a matrícula do aluno surdo na escola e com a colocação de um intérprete de Libras. O sentido da inclusão precisa ser compreendido e aprofundado sob outros olhares. E as políticas públicas precisam acompanhar o debate sobre a educação de surdos numa perspectiva bilíngue, onde a Libras e reconhecida como sua primeira língua (não somente na lei), e o português como segunda língua, e não a única forma de acesso ao conhecimento.

Preocupa-nos principalmente que os professores não saibam libras para se comunicarem com os alunos surdos, pois os impactos disso na aprendizagem destes alunos são evidentes. Não se pode delegar aos intérpretes uma responsabilidade que é docente. E na ausência dos intérpretes ficar o surdo condenado ao esquecimento.

A partir da pesquisa realizada foi possível observar que as EPs em João Pessoa não possuem uma proposta política posta nos PPPs das referidas escolas, bem como não existe uma proposta única definida pela Secretaria de Educação a ser adaptada por cada escola. Assim, fica a critério do gestor escolar definir estratégias e ações que ele julga inclusiva, mas estes gestores pouco ou nada sabem sobre inclusão de surdos. Portanto, no geral, não há ações em prol da inclusão do surdo nas escolas consideradas referências para recebê-los.

As escolas buscam ser inclusivas, mas suas estratégias estão desencontradas, não se relacionando com a legislação vigente, nem tampouco com as reivindicações da comunidade surda. As escolas não priorizam o AEE - Atendimento Educacional Especializado como alternativa inclusiva para surdos, como está disposto na legislação em nível nacional, nem colocam o surdo no centro das discussões sobre o assunto. 
Em nenhuma escola encontramos as três modalidades previstas na lei: ensino de libras, ensino em libras e ensino de português. Além disso, a presença de intérprete em todas as turmas onde existam surdos não está garantida. E a presença de instrutor surdo para garantir a disseminação da Libras na comunidade ouvinte (alunos, professores e funcionários) não se efetiva na prática. Desse modo, evidenciamos que as escolas públicas de João Pessoa não atendem as necessidades dos estudantes surdos e não atendem ao que prevê as leis brasileiras.

Chamamos atenção para o fato de que há uma tendência no aumento de matrículas de pessoas surdas no ensino regular, em todos os níveis, e de que tal efeito vem sendo interpretado como fenômeno inclusivo. No entanto, o que não se verifica nestes dados, é a qualidade desta inserção social, as reais possibilidades de aprendizagem para os sujeitos com deficiência auditiva e os significados desta "inclusão", a partir do olhar dos próprios indivíduos surdos.

\section{REFERÊNCIAS}

BRASIL. Lei de Diretrizes e Bases da Educação Nacional. LDB № 9394. Brasília: Ministério da Educação, 1996.

. Diretrizes Curriculares Nacionais para a educação especial na educação básica. Brasília: MEC/SESSP, 2001.

. Lei 10.436. Dispõe sobre a Língua Brasileira de Sinais. Brasília. MEC, 2002.

2005.

Decreto N.o 5626. Dispõe sobre a Língua Brasileira de Sinais. Brasília: MEC/SEESP,

Decreto N.․ 6571. Dispõe sobre o Atendimento Educacional Especializado. Brasília: MEC/SEESP, 2008.

. Política Nacional de Educação Inclusiva. Brasília: MEC/SEESP, 2008.

. Censo demográfico. Brasília: Senado, 2010.

. Decreto N. 7611 . Dispõe sobre a Educação Especial e o atendimento educacional especializado. Brasília: MEC/SEESP, 2011.

DAMÁZIO, Mirlene F. M. Atendimento educacional especializado: Pessoa com surdez. Brasília: SEESP/SEED/MEC, 2007.

FERNANDES, E. Problemas linguísticos e cognitivos do surdo. Rio de Janeiro: Agir, 1995.

GLAT, R. Inclusão total: mais uma utopia? In: Revista Integração. Ano 8, n. 20. MEC SSEESP,1998, p. 27-28. 
LACERDA, Cristina F. B de. A inclusão escolar de alunos surdos: o que dizem alunos, professores e intérpretes sobre esta experiência. Disponível em: http://www.scielo.br/pdf/ccedes/v26n69/a04v2669.pdf. Acesso em: 23 de novembro de 2013.

LACERDA, C.B.F.; MANTELATTO, S.A.C. As diferentes concepções de linguagem na prática fonoaudiológica junto a sujeitos surdos. In: LACERDA, C.B.F.; NAKAMURA, H.;

LIMA, M.C. (Org.). Fonoaudiologia: surdez e abordagem bilíngue. São Paulo: Plexus, 2000.

MANTOAN, Maria T. E. Caminhos pedagógicos da inclusão. São Paulo: Memnon, edições científicas, 2001.

SANTIAGO, Sandra A.S. A história da exclusão de pessoas com deficiência: elementos sócio econômicos, educacionais e religiosos. Joao Pessoa: Editora Universitária, 2011.

SASSAKI, R. K. Inclusão: construindo uma sociedade para todos. Rio de Janeiro: WVA, 1997.

SKLIAR, Carlos (org.). Atualidade da Educação Bilingue para surdos: processos e projetos pedagógicos. Porto Alegre: Mediação, 2009.

VIEIRA, Evaldo. Democracia e política social. São Paulo: Cortez, 1992.

VIEIRA, Sofia L. Política educacional em tempos de transição (1985-1995). São Paulo: Plano, 2000. 